\title{
Pengaruh Pelatihan Pemberian ASI Ekslusif terhadap Pengetahuan Menyusui Kelompok Pendukung ASI di Desa Mekargalih dan Cipacing Kecamatan Jatinangor Kabupaten Sumedang
}

\author{
Sri Astuti, ${ }^{1}$ Ari Indra Susanti, ${ }^{1}$ Tina Dewi Judistiani²
}

\begin{abstract}
${ }^{1}$ Departemen Ilmu Kesehatan Masyarakat Fakultas Kedokteran Universitas Padjadjaran
${ }^{2}$ Departemen Epidemiologi dan Biostatistika Fakultas Kedokteran Universitas Padjadjaran
\end{abstract}

\begin{abstract}
Abstrak
Survei kesehatan (Riskesdas) tahun 2010 melaporkan bahwa ibu yang melakukan pemberian ASI eksklusif hanya sekitar 15,3\% di Indonesia. Pada tahun 2013, ibu yang melakukan pemberian ASI eksklusif sebesar 25,4\% di wilayah Jawa Barat. Angka ini semakin menurun terutama di tingkat kecamatan. Hal ini berperan dalam peningkatan prevalensi gizi buruk pada anak-anak di bawah usia 6 bulan yang akhirnya akan berdampak pada peningkatan angka kematian anak. Oleh karena itu, penelitian ini bertujuan untuk mengetahui pengaruh pelatihan pemberian ASI Eksklusif terhadap pengetahuan menyusui Kelompok Pendukung ASI (KP-ASI) yang dilaksanakan di Desa Mekargalih dan Cipacing, Kecamatan Jatinangor kabupaten Sumedang. Metode penelitian yang digunakan adalah quasi eksperimental pretest posttest design yang dilaksanakan pada bulan Oktober 2014. Pengambilan sampel dilakukan dengan tehnik purposive sampling sebanyak 100 responden dari Desa Mekargalih dan Desa Cipacing. Penelitian ini menggunakan data primer dengan memberikan kuesioner kepada responden sebelum dan sesudah diberikan pelatihan dan pembentukan KP-ASI. Untuk menganalisis pengaruh (hubungan) pelatihan pemberian ASI Eksklusif terhadap pengetahuan menyusui KP-ASI digunakan analisis T-Test dan Rank Spearman. Hasil penelitian didapatkan pengetahuan tentang pemberian ASI pada kelompok pendukung ASI di kedua desa sebelum dan setelah pelatihan terbanyak kurang, dan menunjukkan pengaruh yang bermakna pelatihan pemberian ASI Eksklusif terhadap pengetahuan menyusui KP-ASI $(\mathrm{p}<0.05)$. Simpulan pembentukan dan pelatihan KP-ASI dapat meningkatkan pengetahuan menyusui KP-ASI sehingga mendorong para ibu untuk melakukan pemberian ASI Eksklusif.
\end{abstract}

Kata kunci: ASI Ekslusif, Pengetahuan, KP-ASI

\section{Effect of Breastfeeding Exclusive Training on Knowledge Breastfeeding Support Groups Asi}

\begin{abstract}
General health survey in Indonesia reported that in 2010, only around $15.3 \%$ mothers gave exclusive breastfeeding. This number was steadily decreased when reaching district level. This led to increased prevalence of malnutrition until $11.7 \%$ among children under 6 months old that in the future will play a role in increasing children mortality rate. The objective of this study was to give counseling and training for breastfeeding support group and evaluate its impact on their knowledge regarding breastfeeding in Mekargalih and Cipacing Village, Jatinangor District, Sumedang Regency. This study was Quasi eksperiment pretest posttest design. Questionnaire regarding knowledge of breastfeeding was used prior to counseling and training among 100 mothers selected with purposive sampling. After counseling and training, knowledge was evaluated again using another questionnaire. To determine the effect (the relationship) between training with knowledge of breastfeeding used analysis of T-test and Spearman Rank. There was significant increase of knowledge $(p<0.05)$ after counseling and training for breastfeeding support group. Counseling and training for breastfeeding support group could give better knowledge to encourage mothers to do exclusive breastfeeding.
\end{abstract}

Keywords: Exclusive Breastfeeding, Knowledge, Support Group

Korespondensi:

Dra. Sri Astuti, M.Kes

Departemen Ilmu Kesehatan Masyarakat Fakultas Kedokteran Universitas Padjadjaran

Jalan Prof. Dr. Eyckman No. 38 Bandung 40161

Mobile : 08122353282

Email : sriastuti29a@gmail.com 


\section{Pendahuluan}

Air Susu Ibu (ASI) merupakan makanan terbaik bagi bayi. Pemberian ASI dapat menyebabkan terjadinya kontak fisik dan hisapan bayi akan merangsang produksi ASI terutama pada 30 menit pertama setelah lahir. Pada periode ini ASI saja sudah dapat memenuhi kebutuhan gizi bayi. Walaupun pemberian ASI segera sangat penting, tetapi hanya $29 \%$ ibu yang melakukan. ${ }^{1}$ Menyusui telah menjadi isu kesehatan masyarakat yang utama. Di Indonesia terutama di kota-kota besar terjadi penurunan pemberian ASI, bukti - bukti penurunan pemberian ASI di Negara maju telah banyak dikemukakan, antara lain di Amerika Serikat pada permulaan abad ke-20 sekitar $71 \%$ bayi mendapat ASI sampai umur kurang dari 6 bulan, angka ini menurun menjadi $25 \%$ pada ibuibu dengan sosio ekonomi sedang dan $5 \%$ pada sosio ekonomi baik. Data Riset Kesehatan Dasar (Riskesdas) Tahun 2010 menunjukkan pemberian ASI di Indonesia saat ini memprihatinkan, persentase bayi yang menyusu eksklusif sampai dengan 6 bulan hanya $15,3 \%$. Hal ini disebabkan kesadaran masyarakat dalam mendorong peningkatan pemberian ASI masih relatif rendah. ${ }^{2}$

Cakupan ASI Eksklusif di Jawa Barat pada tahun 2013 sebesar $25,4 \%$ sedangkan di Kabupaten Sumedang cakupan ASI Eksklusif sebesar 6,1\%.3 Cakupan ASI Eksklusif pada tahun 2013 di wilayah kerja Puskesmas Jatinangor yaitu desa Mekargalih sebesar $56,25 \%$ dan desa Cipacing sebesar 42,50 \%. ${ }^{4}$

Permasalahan dalam pemberian ASI sebagian besar karena kurangnya pengetahuan ibu antara lain tidak tahu manfaat kolostrum sehingga dibuang, pemberian makanan pendamping (MP) ASI terlalu dini atau terlambat, pemberian MPASI sebelum ASI, pemberian ASI terhenti karena ibu kembali bekerja. World Health Organization (WHO) secara aktif mempromosikan menyusui sebagai sumber gizi terbaik bagi bayi dan anak. WHO dan United Nations Children's Fund (UNICEF) menganjurkan pemberian ASI secara eksklusif, yaitu ASI saja sampai bayi berusia 6 bulan. ${ }^{5}$ Namun ada beberapa kondisi dan situasi yang menyebabkan ibu tidak dapat menyusui dengan benar, termasuk pemberian ASI ekslusif, sehingga memerlukan dukungan baik dari bidan, keluarga dan lingkungan masyarakat untuk kesiapan menyusui. ${ }^{6,7}$

Penelitian juga menunjukkan bahwa inisiatif dukungan sebaya di mana saran diberikan oleh teman yang berpengalaman dan terlatih dapat mempromosikan dan meningkatkan pemberian ASI. Selain itu di Amerika Serikat banyak program pelatihan untuk ibu yang bertujuan meningkatkan kesadaran menyusui, meningkatkan durasi menyusui di kalangan ibu, meningkatkan kepercayaan diri ibu untuk menyusui. Kelompok tersebut telah dikembangkan dan banyak ibu telah menjalani pelatihan untuk menjadi peer councellor. Selain di rumah sakit, dukungan pun diberikan oleh bidan komunitas, memasyarakatkan menyusui di lingkungan sosial sangat mendukung kesiapan ibu untuk menyusui ${ }^{6}$

Strategi untuk mendukung perempuan agar menyusui antara lain memberikan penyuluhan, bimbingan, konseling. Pemberian ASI perlu diprogramkan dengan mendirikan Kelompok Pendukung ASI (KP-ASI) dan Kader Kelompok Pendukung ASI (KKP-ASI) sebagai kegiatan yang dapat mendukung keberhasilan ibu menyusui. ${ }^{7}$ Kelompok Pendukung ASI adalah kumpulan ibu-ibu relawan yang seminat terhadap peningkatan pengguna ASI dan termotivasi untuk memberikan ASI. KP-ASI dapat dikelola secara mandiri atau oleh suatu organisasi di masyarakat.

Demikian halnya di Indonesia dan telah dilaksanakan kelas ibu hamil dan kelas ibu balita sebagai upaya dalam pemberian dukungan dan pelatihan kepada ibu hamil dan ibu balita agar ibu menyusui secara ekslusif. Selain melalui kelas ibu hamil Pemerintah menganjurkan agar setiap ibu hamil diberikan buku KIA sebagai informasi yang mampu meningkatkan pengetahuan ibu hamil serta dapat merubah sikap dan perilaku ibu hamil. ${ }^{8,9}, 10$ Namun ada beberapa kondisi dan situasi yang menyebabkan ibu tidak dapat menyusui dengan benar, termasuk pemberian ASI ekslusif, sehingga memerlukan dukungan baik dari bidan, keluarga dan lingkungan masyarakat untuk kesiapan menyusui. ${ }^{7}$ Dukungan suami yang positif akan meningkatkan pemberian ASI ekslusif. ${ }^{11}$ Dukungan konselor dalam KP -ASI dapat dilakukan oleh bidan atau tenaga kesehatan lain. Dukungan bidan (professional) untuk membangun rasa percaya diri dan motivasi ibu untuk menyusui. Hasil penelitian Dyson dkk (2006) menyatakan bahwa perempuan dapat dipengaruhi secara positif atau negatif oleh pengalaman keluarga dan teman-teman, pesan melalui media dan saran dari bidan atau dokter. Karena pelayanan kesehatan sekarang memiliki sumber daya yang berharga ini, yang mengidentifikasi secara signifikan hambatan menyusui, strategi lokal dan nasional yang dapat dikembangkan untuk mendukung perempuan dalam keputusan menyusui. Perempuan yang didukung secara efektif untuk menyusui akan memperpanjang masa menyusui, karena terpapar model peran positif. Program dukungan untuk memberdayakan perempuan yang tinggal di lingkungan sosial masyarakat tidak boleh dikecualikan dan tidak dianggap remeh. ${ }^{6,11}$ Bidan adalah salah satu praktisi kesehatan seperti 
diuraikan dalam The Royal College of Midwifery (RCM 2001) mengenai peran bidan dalam kesehatan masyarakat, bahwa semua bidan terlibat saat memberikan pelayanan kebidanan kepada individu dan kelompok perempuan. Misalnya, bidan memberikan informasi dan rekomendasi berbagai isu, termasuk makan makanan yang sehat, latihan, melakukan skrining, dukungan untuk berhenti merokok dan promosi menyusui. Kelahiran merupakan masalah kesehatan masyarakat karena dampaknya pada kesehatan dan kesejahteraan wanita, bayi, anak-anak, keluarga. ${ }^{12}$

Berdasar latar belakang yang telah dikemukakan di atas, dan melalui observasi di lapangan, maka kami melakukan pembentukan Kelompok Pendukung ASI (KP-ASI) dan melaksanakan pelatihan pemberian ASI eksklusif di desa Mekargalih dan desa Cipacing kecamatan Jatinangor kabupaten Sumedang Adapun tujuan dari penelitian ini, yaitu untuk mengetahui pengaruh pelatihan terhadap pengetahuan pemberian ASI Kelompok Pendukung ASI dan untuk mengetahui hubungan pengetahuan tentang pemberian ASI ekslusif kelompok pendukung ASI dengan karakteristik berdasarkan pendidikan peserta di desa Mekargalih dan desa Cipacing.

\section{Metode}

Desain yang digunakan dalam penelitian ini adalah penelitian kuantitatif dengan Quasi eksperiment pretest posttest design.

Populasi adalah ibu hamil, ibu menyusui dan ibu balita yang ada di desa Mekargalih dan desa Cipacing kecamatan Jatinangor sebesar 578 orang dilaksanakan pada Oktober 2014. Sampel adalah ibu hamil, ibu menyusui dan ibu balita yang berada di desa Mekargalih dan Desa
Cipacing. Besar Sampel untuk ditetapkan secara purposive di desa Mekargalih (14 RW) sebesar 50 orang di setiap RW sebanyak 3-5 orang yang terdiri dari ibu hamil dan ibu menyusui. Sedangkan desa Cipacing (18 RW) sebesar 50 orang di setiap RW 2-3 orang yang terdiri dari ibu hamil dan menyusui. Sampel yang diambil sesuai dengan kriteria inklusi, yaitu ibu hamil trimester 1 sampai dengan 3 dan ibu menyusui yang mempunyai 0-6 bulan. Kriteria eksklusi, yaitu ibu hamil dan ibu menyusui yang tidak hadir pada waktu pelatihan KP-ASI. Pengumpulan data secara kuantitatif dengan memberikan kuesioner, dan evaluasi KP-ASI secara wawancara. Analisis yang digunakan untuk mengetahui karakteristik subyek penelitian dan untuk melihat variable pengetahuan dengan menghitung distribusi frekuensi. Analisis bivariat untuk menguji hubungan antara pelatihan KP-ASI dengan pengetahuan menyusui, statistik yang digunakan adalah T-Test dan Korelasi Spearman Rank.

Penelitian ini telah disetujui oleh Komite Etik Penelitian Kesehatan Fakultas Kedokteran Universitas Padjajaran No: 487/UN6.C2.1/ KEPK/PN/2014

\section{Hasil}

Penelitian telah dilakukan terhadap 100 responden dari2 desayaitudesaMekargalihdandesaCipacing. Dari tabel 1 menunjukkan bahwa pengetahuan responden tentang pemberian ASI sebelum dan sesudah pelatihan pada kedua desa terbanyak kurang, tidak ada yang mempunyai pengetahuan baik. Berdasarkan Tabel 2 terdapat pengaruh yang bermakna pelatihan pemberian ASI terhadap pengetahuan menyusui Kelompok Pendukung ASI $(p<0.001)$. Berdasarkan Tabel 3 terdapat

Tabel 1 Pengetahuan Pemberian ASI Sebelum dan Sesudah Pelatihan KP-ASI

\begin{tabular}{lcccc}
\hline \multirow{2}{*}{$\begin{array}{c}\text { Variabel } \\
\text { Pengetahuan }\end{array}$} & \multicolumn{2}{c}{ Mekargalih } & & \\
\cline { 2 - 5 } & & & & \\
& Sebelum pelatihan & $\begin{array}{c}\text { Sesudah } \\
\text { pelatihan }\end{array}$ & $\begin{array}{c}\text { Sebelum } \\
\text { pelatihan }\end{array}$ & Sesudah pelatihan \\
& & $\mathrm{n}(\%)$ & $\mathrm{n}(\%)$ & $\mathrm{n}(\%)$ \\
\hline Baik & $\mathrm{n}(\%)$ & $0(0)$ & $0(0)$ & $0(0)$ \\
Cukup & $\mathrm{pelatihan}$ & $3(6,1)$ & $8(16,3)$ \\
Kurang & $\mathrm{n}(\%)$ & Sebelum pelatihan & $41(83,7)$ \\
Total & $\mathrm{n}(\%)$ & Sesudah pelatihan & $46(93,9)$ & $49(100)$ \\
\hline
\end{tabular}


Sri Astuti : Pengaruh Pelatihan Pemberian ASI Ekslusif terhadap Pengetahuan Menyusui Kelompok Pendukung Asi di Desa Mekargalih dan Cipacing Kecamatan Jatinangor Kabupaten Sumedang

Tabel 2 Pengaruh Pelatihan Pemberian ASI terhadap Pengetahuan Menyusui Kelompok Pendukung ASI desa Mekargalih dan Desa Cipacing

\begin{tabular}{lccl}
\hline \multicolumn{1}{c}{ Pengetahuan } & $\begin{array}{c}\text { Sebelum pelatihan } \\
\mathbf{n}(\mathbf{\%})\end{array}$ & $\begin{array}{c}\text { Sesudah pelatihan } \\
\mathbf{n}(\mathbf{\%})\end{array}$ & Nilai p \\
\hline Cukup & $7(7)$ & $19(19)$ & \\
Kurang & $93(93)$ & $81(81)$ & 0.000 \\
Total & $100(100)$ & $100(100)$ & \\
\hline
\end{tabular}

hubungan yang bermakna pengetahuan tentang pemberian ASI eksklusif kelompok pendukung ASI dengan karakteristik responden berdasarkan pendidikan $(\mathrm{p}<0.001)$.

\section{Pembahasan}

Hasil analisis secara deskriptif dan uji statistik pada penelitian ini didapatkan pengetahuan responden tentang pemberian ASI sebelum dan sesudah pelatihan pada kedua desa terbanyak kurang, tidak ada yang mempunyai pengetahuan baik. Pengetahuan yang kurang antara lain tentang kolostrum, penyimpanan ASI yang diperah, dan masalah-masalah menyusui pada ibu seperti puting lecet, puting yang datar atau tenggelam. Terdapat pengaruh yang bermakna pelatihan pemberian ASI terhadap pengetahuan menyusui Kelompok Pendukung ASI $(\mathrm{p}<0.001)$. Penelitian ini menunjukkan bahwa rendahnya pemberian ASI ekslusif di desa wilayah kerja PKM Jatinangor kecamatan Jatinangor berkaitan dengan pengetahuan yang rendah (data Profil PKM Jatinangor, 2013). Dalam meningkatkan pemberian ASI dibutuhkan bantuan dan informasi yang mendukung, sehingga perempuan merasa yakin dapat menyusui bayinya dengan sukses ${ }^{13}$. Hal ini sesuai dengan teori menurut Notoatmodjo, salah satu faktor yang mempengaruhi pengetahuan seseorang adalah informasi. Informasi yang diperoleh dari petugas kesehatan dapat memberikan pengaruh jangka pendek (immediate impact) sehingga menghasilkan perubahan atau peningkatan pengetahuan.

Hasil penelitian Exsi Setyowati dan Faizah Betty Rahayu terdapat hubungan tingkat pengetahuan tenaga kesehatan tentang ASI Eksklusif berhubungan signifikan dengan kemampuan dalam memberikan pendidikan kesehatan pada ibu prenatal. ${ }^{14}$ Untuk merubah pengetahuan sikap dan perilaku adalah dengan pendidikan dan pelatihan. Mengajarkan dan mendemostrasikan halhal yang mendetail dan penting mengenai menyusui membutuhkan waktu yang lama. ${ }^{10}$

Berdasarkan hasil penelitian ini didapatkan hubungan yang bermakna pengetahuan tentang pemberian ASI eksklusif kelompok pendukung ASI dengan karakteristik responden berdasarkan pendidikan $(p<0.001)$. Pengetahuan yang kurang terbanyak pada responden dengan pendidikan SMP/Mts dan SLTA, selain itu juga terdapat pada responden dengan pendidikan SD. Setelah diintervensi dengan metode pelatihan yang bervariatif masih juga terdapat pengetahuan yang kurang.

Kepandaian menyusui tidak dibawa dari lahir, bukan suatu instink, tapi seni yang harus dipelajari ${ }^{10}$. Diperlukan pengetahuan petugas kesehatan yang cukup untuk dapat membina ibu menyusui. Masa menyusui adalah masa yang paling sensitif dalam kehidupan ibu. Baik secara fisik ataupun emosional. Begitu ibu mulai menyusui, ibu butuh lingkungan yang supportif, yang mendukung ibu dari berbagai keraguan

Tabel 3 Hubungan Pengetahuan tentang Pemberian ASI Ekslusif Kelompok Pendukung ASI dengan Karakteristik Responden Berdasarkan Pendidikan

\begin{tabular}{lccc}
\hline \multirow{2}{*}{ Pendidikan } & \multicolumn{2}{c}{ Pengetahuan } & Nilai p \\
\cline { 2 - 3 } & $\begin{array}{c}\text { Cukup } \\
\text { n (\%) }\end{array}$ & $\begin{array}{c}\text { Kurang } \\
\text { n (\%) }\end{array}$ & \\
\hline SD/MI & $6(6)$ & $9(9)$ & 0.000 \\
SMP/MTs & $9(9)$ & $45(45)$ & \\
SLTA & $4(4)$ & $24(24)$ & \\
PT & $0(0)$ & $3(3)$ & \\
Total & $19(19)$ & $81(81)$ & \\
\hline
\end{tabular}


dan kritikan. Hal ini disebabkan oleh minimnya pengetahuan tentang menyusui dan kadang dipengaruhi oleh anggapan yang salah tentang payudara dari segi sexual. Bidan dapat segera mengajarkan teknik menyusui untuk mengurangi masalah menyusui sehingga ibu merasa percaya diri. ${ }^{16}$ Dengan demikian diperlukan, dorongan dan dukungan positif dari semua pihak, agar ibu merasa nyaman dan percaya diri untuk menyusui.

Pelatihan pemberian ASI ekslusif selain meningkatkan pengetahuan, juga merupakan pemberian dukungan kepada ibu untuk menyusui, hal ini seperti yang diungkapkan dalam hasil penelitian Caroline bahwa dukungan menyusui dari bidan dan ibu-ibu itu sendiri sangat diperlukan dan berpengaruh terhadap pengalaman menyusui. ${ }^{15}$ Hasil penelitian yang banyak memberikan dukungan adalah suami. ${ }^{17}$

Pengetahuan dapat memotivasi ibu untuk menyusui ditumbuhkan dan ditingkatkan dengan memberikan promosi kesehatan atau penyuluhan secara luas di masyarakat melalui berbagai media seperti televisi, radio, majalah, tabloid, surat kabar dan buku-buku tentang pemberian ASI. $^{7}$

Kelompok Pendukung ASI (KP-ASI) telah memberikaninformasitentangASI ekslusifkepada para ibu menyusui yang datang ke posyandu, kepada anggota keluarganya, dan kunjungan ke rumah ibu yang baru melahirkan (tetangga).

Kelompok Pendukung ASI merupakan kegiatan inovasi, hal ini diperlukan untuk mendukung ibu (peer support). Ibu hamil dan menyusui membutuhkan kepercayaan, penerimaan, pengakuan, dan penghargaan terhadap persaannya. Suasana saling mendukung mudah dibangun dalam kelompok sebaya yang mempunyai pengalaman dan situasi lingkungan yang sama. Peserta pelatihan telah melakukan perannya sebagai motivator secara sukarela, dan ingin meningkatkan pengetahuan dan keterampilannya seperti diuraikan di atas bahwa kegiatan ini diharapkan diadakan secara rutin.

Simpulan pada penelitian ini adalah pembentukan dan pelatihan KP-ASI dapat meningkatkan pengetahuan menyusui KPASI sehingga mendorong para ibu untuk melakukan pemberian ASI Eksklusif.

Saran untuk penelitian ini, yaitu untuk meningkatkan pengetahuan tentang pemberian ASI dapat terus dilakukan dengan melibatkan mahasiswa Diploma Kebidanan Unpad yang sedang praktik berkolaborasi dengan bidan desa setempat dan PKM untuk memberikan promosi atau penyuluhan tentang pemberian ASI. Kegiatan Kelompok Pendukung ASI dapat dilaksanakan pada kegiatan Posyandu dengan mengikuti alur posyandu. Untuk kegiatan peningkatan penggunaan ASI paling mungkin dilakukan di meja IV (IV-B). Diperlukan maintenance dan mentoring secara berkala dan berkelanjutan oleh Kepala Puskesmas, Kepala Desa, Bidan Desa, Petugas gizi Puskesmas untuk membantu, mencari solusi dan keberlangsungan KP-ASI di wilayahnya. Kepala Desa sebagai penanggung jawab hendaknya selalu mewajibkan ibu menyusui datang ke Posyandu dan meminta kader melaksanakan kegiatan pemberianASI. Dukungan dari Dinas Kesehatan Kabupaten Sumedang sangat diperlukan untuk pembentukan KP-ASI di desa lainnya minimal di wilayah kecamatan Jatinangor dalam bentuk dana dan supervisi kegiatan KP-ASI secara berkala dan berkelanjutan

\section{Daftar Pustaka}

1. USAID- Indonesia. Dalam Satu Jam Pertama. Health Servis Program: Bandung; 2009.

2. Depkes RI. Banyak sekali manfaat ASI bagi bayi dan ibu. Pusat Komunikasi Publik Kementrian Kesehatan RI: Jakarta; 2008.

3. Dinas Kesehatan Provinsi Jawa Barat. Cakupan Pelayanan Kesehatan. Dinkes: Bandung; 2013.

4. Puskesmas Jatinangor. Profil Puskesmas DTP Jatinangor: Jatinangor; 2013.

5. Tengku Alina, tengku Ismail, Zaharah Sulaiman. Reliability and validity of a Malayversion questionnaire assessing knowledge of breastfeeding. Malaysian J Med Sci: 2010; 17(3): 32-39.

6. Jinny Briant. Littlehampton Sure Start: An Evaluation of the Breastfeeding Peer Support A. London: Report by the Research Department National Children's Bureau; 2005.

7. Perinasia. Manajemen Laktasi. Edisi ke-3: Jakarta; 2007.

8. Caroline Lamontagne, Anne-Marie Hamelin and Monik St-Pierre. The breastfeeding experience of women with major difficulties who use the services of a breastfeeding clinic: a descriptive study: International Breastfeeding Journal; 2008.

9. Kemenkes RI.Pedoman Pelaksanaan kelas ibu hamil. Direktorat Jenderal Bina Gizi dan KIA: Jakarta; 2011.

10. Fatmah. Teori \& Penerapan Media Komunikasi, Informasi dan Edukasi Gizi. Penerbit Erlangga: Jakarta; 2014.

11. I. A. Ekanem , A. P. Ekanem A. Asuquo ,V. O. Eyo . Attitude of Working Mothers to Exclusive Breastfeeding in Calabar Municipality, Cross River State, Nigeria. Journal of Food Research: May 2012; Vol. 1, No. 2. 

Mekargalih dan Cipacing Kecamatan Jatinangor Kabupaten Sumedang

12. Stockdale J, Sinclair M, Kernohan WG, Dunwoody L,Cunningham JB, Lawther L. Assessing the impact of midwives' instruction: the breastfeeding motivational instructional measurement scale, Evidence Based Midwifery: 2008,-6(1): 2-5

13. Grace Edwards, Sheena Byrom. Essential Midwifery Practice: Public Health. Blackwel Publishing; 2007.

14. Exsi Setyowati dan Faizah Betty. Berita Ilmu Keperawatan ISSN 1979-2697: Juni 2008; Vol .1 No.2, 51-57.

15. Caroline A Bäckström, Elisabeth I Hertfelt
Wahn and Anette C Ekström. Two sides of breastfeeding support: experiences of women and midwives. International Breastfeeding Journal 2010, 5:20.

16. Jenny Ingram, Debbie Johnson, Marion Copeland, Cathy Churchill, Hazel Taylor. The development of a new breast feeding assessment tool and the relationship with breast feeding self-efficacy. 2014.

17. Persons who had most supported and encouraged women throughout breastfeeding experience. PubMed Central: Breastfeed J.2008; Vol.5, Hal. 10. 